\title{
Detection of Mutations in the 81 Bp RRDR of Rpob Gene in Mycobacterium Tuberculosis Clinical Isolates Using Xpert ${ }^{\circledR}$ MTB/RIF in Basra/Iraq
}

\author{
Ghorob S Khudhair ${ }^{1}$, Khairallah A.S Mohammed ${ }^{1}$, Dheyaa Bekheet Al-Rabeai ${ }^{2}$ \\ \{ghorob64@gmail.com,dr.kmohammed@stu.edu.iq, Dheyaabukheet@yahoo.com\} \\ Department of Medical Lab Technology, College of Health and Medical Technology, Southern \\ Technical University, Iraq $^{1}$ \\ Advisory Clinic for Chest Diseases and Respiratory/ Basra ${ }^{2}$
}

\begin{abstract}
In Iraq, the Xpert ${ }^{\circledR}$ MTB/RIF test is now being utilised to detect rifampicinresistant Mycobacterium tuberculosis (MTB) isolates. Rifampicin resistance is assessed using five overlapping probes in the Rifampicin Resistant Determinant Region (RRDR) of the rpoB gene (A, B, C, D, E). From January 2016 to December 2020, data was gathered from specimens obtained and evaluated using conventional methods and the Xpert ${ }^{\circ}$ MTB/RIF assay at the Advisory Clinic for Chest Diseases and Respiratory in Basra province. Among the 2542 positive samples for MTB, rifampicin resistance was detected in $57(2.24 \%)$ specimens, of which full data for $44 \mathrm{RR}-\mathrm{TB}$ patients is available. Of the 44 RR-TB patients, 35 (79.5\%) were retreatment cases, and the most common $r p o B$ mutations were in the region of Probe E (70.5\%), followed by Probe B (11.3\%), Probe A, and D (9.1\%) for each. Mutations in Probe C were not observed.
\end{abstract}

Keywords: Rifampicin-resistance, $r p o B$, Xpert ${ }^{\circledR}$ MTB/RIF assay, Basra.

\section{Introduction}

Tuberculosis (TB) is one of the most infectious bacterial diseases causing a public health threat. It is estimated that 10.0 million at a rate of 132 per 100000 population new cases of TB occurred in 2019 with high mortality, resulting in 1.2 million (16 per 100000 population) death globally [1]. According to the WHO report (2019), the incidence of TB in the Middle East is 810000 at a rate of 115 per 100000 population and in Iraq 16000 at a rate of 42 per 100000 population [1]. Rifampicin is possibly the utmost important drug in the control and treatment of tuberculosis (TB) [2]. Treatment of TB has become more difficult since the emergence and spreading of multidrug-resistant (MDR) strains [2]. In 2019, WHO reported that the global MDR/RR-TB incidences are 484000 at a rate of 6.4 and in Iraq 1100 at a rate of 2.9 per 100000 population. Hence, to launch a proper effective treatment, it is of great importance to promoting fast and reliable diagnostic assay to detect and to assess the resistance of $M$. tuberculosis strains against main drugs. Conventional methods were commonly used to identify multidrug-resistant (MDR) strains. However, many limitations of the traditional methods of diagnosis of RR-TB such as time-consuming, lack of laboratory infrastructures, and biosafety make them difficult to be applicable, especially in rural settings [3]. WHO endorsed a molecular assay (Xpert assay) which can detect Mycobacterium tuberculosis and rifampicin resistance within a few hours and does not require high technical expertise and a high standard of biosafety measures [4]? 
In this study, we studied the prevalence of RIF-resistant TB and the dominant site mutation types at RRDR in the $r p o B$ gene of rifampicin-resistant MTB strains isolated from specimens of patients diagnosed to have TB in Basra/Iraq, using Xpert ${ }^{\circledR}$ MTB/RIF assay.

\section{Materials and Methods}

The research was carried out in Basra, Iraq's third largest city, with a population of over 3 million people. The data for the study came from the Advisory Clinic for Chest Diseases and Respiratory (ACCDR), the sole health centre in Basra province, Iraq, that deals with tuberculosis patients. From January 2016 to December 2020, data was gathered from specimens obtained and evaluated using the Xpert巴 ${ }^{\circledR}$ MTB/RIF assay at the Advisory Clinic for Chest Diseases and Respiratory (ACCDR) in Basra province. The patients were clinically diagnosed in CCDR, and sputum samples were examined microscopically for acid-fast bacilli (AFB), cultured on Lowenstein-Jensen solid medium, and subjected to conventional drug susceptibility tests [5]. Following that, the samples were run through the GeneXpert MTB/RIF test according to the manufacturer's recommendations (Cepheid, Sunnyvale, CA, USA). Molecular beacons are used in five overlapping areas of the rpoB DNA region by the GeneXpert MTB/RIF. The probes can detect mutations in codons 507-511 (Probe A), 511-518 (Probe B), 518-523 (Probe C), 523-529 (Probe D), and 529-533 (Probe E) (Probe E). The Basra Health Authority's Research and Development Committee approved the study..

\section{Results}

Mycobacterium tuberculosis was found in 2542 samples between 2016 and 2020, with the highest frequency (35\%) in the 15-34 year old age group. Rifampicin resistance was found in 57 of the samples positive for Mycobacterium tuberculosis (2.24 percent ). Only $44 \mathrm{RR}-\mathrm{TB}$ patients have complete data (Table 1). As shown in Table 1, out of 44 patients diagnosed with RR-TB, 35 (79.5\%) were retreatment cases, with the largest frequency (36.4\%) occurring in individuals aged 15 to 34 years. Table 2 reveals that the most common rpoB mutations were found in Probe E (31, 70.5 percent), Probe B $(5,11.3$ percent), Probe A, and Probe D for each of the four probes $(4,9.1$ percent $)$. Probe $\mathrm{C}$ mutations were not found, and no combination of two probes was found in any case.

Table 1. Demographic and clinical characteristics of study RR - TB patients ( $n=44)$.

\begin{tabular}{|c|c|c|}
\hline Characteristics & New cases $(n=9)$ & Relapse $(n=35)$ \\
\hline \multicolumn{3}{|c|}{ Age } \\
\hline$\leq 14$ & 0 & 0 \\
\hline $15-34$ & 4 & 16 \\
\hline $35-54$ & 3 & 12 \\
\hline$\geq 55$ & 2 & 7 \\
\hline \multicolumn{3}{|c|}{ Sex } \\
\hline Female & 3 & 19 \\
\hline Male & 6 & 16 \\
\hline
\end{tabular}




\begin{tabular}{lll} 
Rural & 4 & 14 \\
Urban & 5 & 21 \\
\hline
\end{tabular}

Table 2. Probe types were distributed among clinical variables in 44 RR-TB patients.

\begin{tabular}{|c|c|c|c|c|c|c|c|c|c|}
\hline \multirow{2}{*}{$\begin{array}{l}\text { Probe } \\
\text { types }\end{array}$} & \multicolumn{2}{|c|}{ Treatment history } & \multirow{2}{*}{$\begin{array}{l}\text { Sex } \\
\text { Male }\end{array}$} & \multirow[b]{2}{*}{ Female } & \multicolumn{3}{|c|}{ Age (year) } & \multicolumn{2}{|c|}{ Region } \\
\hline & New & Relapse & & & $\begin{array}{l}15- \\
34\end{array}$ & $\begin{array}{l}35- \\
54\end{array}$ & $\geq 55$ & Rural & Urban \\
\hline A & 0 & 4 & 0 & 4 & 3 & 1 & & 1 & 3 \\
\hline B & 1 & 4 & 2 & 3 & 2 & 1 & 2 & 2 & 3 \\
\hline $\mathrm{C}$ & ND* & ND & - & - & - & - & - & - & - \\
\hline D & 1 & 3 & 2 & 2 & 1 & 3 & 0 & 3 & 1 \\
\hline $\mathrm{E}$ & 7 & 24 & 18 & 13 & 14 & 10 & 7 & 12 & 19 \\
\hline Total & 9 & 35 & 22 & 22 & 20 & 15 & 9 & 18 & 26 \\
\hline
\end{tabular}

*ND $=$ not detected

\section{Discussion}

The present results showed that during the study period $(2016$ - 2020), Mycobacterium tuberculosis was detected in 2542 samples at an average of 508.4 per year. World Health Organization stated a target for tuberculosis case detection for the last 5 years rate at about 43/100,000 population in Iraq [6]. Given that Basra's overall population is expected to be $2,985,073$ in 2019 [7], the expected tuberculosis cases will be around 1,253 people. The average number of diagnosed cases reported in this study was 508.4, which is less than half of the expected figure. This could be due to a lacklustre screening programme or an erroneously high anticipated case detection target.

The age group 15 - 34 years showed the highest frequency of TB $(35 \%)$ and RR-TB $(75 \%)$ among tuberculous patients diagnosed in this study. The high prevalence of TB in adolescence and early adulthood could be because they have a much wider range of social contacts outside of the household increasing the risk of exposure to Mycobacterium tuberculosis [8]. According to previous research, the risk of Mycobacterium TB infection is highest during adolescence and young adulthood $[8,9,10]$. As a result, in addition to suffering from tuberculosis, teenagers and young adults may also contribute to the disease's continuous spread. Furthermore, numerous medical disorders linked to tuberculosis develop throughout adolescence, such as HIV infection, diabetes, mental health issues, or exposure to hazardous chemicals like tobacco [8, 9]. Furthermore, many young women encounter health issues related to pregnancy and delivery, which may raise their TB risk $[10,11]$.

Out of 2542 samples, $57(2.24 \%)$ samples were resistant to rifampicin. World Health Organization stated a target for MDR/RR-TB, for the last 5 years rate at about 3/100,000 population in Iraq [6]. Based on the estimated population in Basra, then the predictable cases of MDR/RR-TB would be about 86.57 patients. The number of patients diagnosed in this study was 57, which is significantly fewer than the projected amount. This could be due to a lacklustre screening programme or an erroneously high anticipated case detection target. The incidence rate of resistance to Rifampicin documented in this study (2.24\%) is lower than that reported by Mohajeri et al. in Iran (14.28\%) [12], Abdel Dayem et al. in Egypt (8\%) [11], Al Ammari et al. in Saudi Arabia (5.9\%) [14] and Al-Mussawi et al. in Basra (7.56\% [15]. These differences could be due the to sample size or using different detection methods. The present results showed that $79.5 \%$ of RR-TB were retreatment cases. These findings were like what has been reported by Liu et al. [16]. The significant rate of rifampicin resistance among retreatment cases seen in 
this study could be attributable to a large number of resistant strains circulating in the community as a result of the large number of previously treated cases.

Rifampicin resistance was identified in this study using the Xpert ${ }^{\circledR}$ MTB/ RIF assay and rpoB gene mutations in the $81 \mathrm{bp}-\mathrm{RRDR}$. The most prevalent mutation was found in codons 529533, which is represented by Probe E (31, 70.5 percent), followed by Probe B, D, and A. These results are compatible with many other studies done in African and Asian countries which reported that sequence 529-533 (probe E) are the most prevalent codons related to RIFresistance $[17,18,19,20]$. However, according to another study conducted in Malawi, the majority of RR cases discovered by the Xpert ${ }^{\circledR}$ MTB/RIF assay were linked to probe B (23/64) and probe $E$ (23/64) [21]. In addition, no RIF resistance related to Probe $C$ was found in this investigation. Probe $\mathrm{C}$ was only seen once, in the study by Metcalfe et al. in Zimbabwe [22], which could be due to the fact that this specific location within RRDR is likely to be less susceptible to drug resistance-causing genetic changes.

The data on the probes that confer RR could be utilised to track drifts over time, identify transmission hotspots, and investigate outbreaks, especially when the RR is lower than mutations outside the Probe E zone. In addition, studies on mutations can aid in the development of new TB medicines. The key limitation of our work was that the rpoB gene was not sequenced, so we were unable to determine the exact rpoB mutations.

\section{Conclusion}

The Probe E region mutations were discovered to be the most prevalent rpoB gene mutations. Probe C-related RIF resistance was not found. The importance of using the Xpert MTB/RIF assay for detecting MTB and rifampicin-resistant bacteria from suspected TB/MDR cases in a timely manner was highlighted in this study. It may provide preliminary information on the mutation pattern of MTB strains resistant to rifampicin. To discover the exact rpoB mutations, more molecular research is required.

\section{References}

[1] Global tuberculosis report 2019. Geneva: World Health Organization; 2019. License: CC BY-NCSA 3.0 IGO.

[2] Connell D.W., M. Berry, G. Cooke, O.M. Kon Update on tuberculosis: TB in the early 21 century. European Respiratory Review June. 201; 20 (120) 7184.

[3] Parsons, L. M., Somoskövi, A., Gutierrez, C., Lee, E., Paramasivan, C. N., Abimiku, A., Spector, S., Roscigno, G., \& Nkengasong, J. Laboratory diagnosis of tuberculosis in resource-poor countries: challenges and opportunities. Clinical microbiology reviews. 2011; 24(2):314-350.

[4] Lawn, S. D. and M. P. Nicol, "Xpert MTB/RIF assay: development, evaluation and implementation of a new rapid molecular diagnostic for tuberculosis and rifampicin resistance, Future Microbiology. 2011; vol. 6, no. 9, pp. 1067-1082.

[5] Mankhi, A. S., Supervised by Hashem, Z. S. Guidelines of Laboratory manual work of tuberculosis in Iraq, Prepared by Ministry of Health. Iraq. Baghdad, 2009.

[6] World Health Organization, Global Tuberculosis Report 2015-2019, World Health Organization, Geneva, 2015, 2016, 2017, 2018, and 2019. 
[7] Central Statistical Organisation. Ministry of Planning. Republic of Iraq. http://cosit.gov.iq/ar/20182019.

[8] Nduba V, Hoog AH, Mitchell E, et al. Prevalence of tuberculosis in adolescents, western Kenya: implications for control programs. Int J Infect Dis 2015; 35: 11-17.

[9] Comstock GW, Livesay VT, Woolpert SF. The prognosis of a positive tuberculin reaction in childhood and adolescence. Am J Epidemiol 1974; 99: 131-138.

[10 Mathad JS, Gupta A. Tuberculosis in pregnant and postpartum women: epidemiology, management, and research gaps. Clin Infect Dis 2012; 55: 1532-1549.

[11] Rendell NL, Batjargal N, Jadambaa N, et al. Risk of tuberculosis during pregnancy in Mongolia, a high incidence setting with low HIV prevalence. Int J Tuberc Lung Dis 2016; 20 : 1615.

[12] Mohajeri P, Norozi B, Atashi S, Farahani A. Anti tuberculosis drug resistance in west of Iran. J Global Infect Dis 2014; 6:114-7.

[13] Abdel Dayem AM, Sharkawy SH, Mohammed Fathy RM, Hassanin OM, Ali A. Detection of drugresistant Mycobacterium tuberculosis using Geno Type MTBDR plus assay in smear positive cases. Egypt J Chest Dis Tuberc. 2019; 68:284-9.

[14] Al Ammari M, Al Turaiki A, Al Essa M, Kashkary AM, Eltigani SA, Ahmed AE. Drug resistant tuberculosis in Saudi Arabia: an analysis of surveillance data 2014-2015. Antimicrob Resist Infect Control. 2018 Jan 22;7:12.

[15] Al-Mussawi Abdulameer Abuallh, Naael Hussein Ali, Alaa Hussein Abed. Molecular quantification of Rifampicin-resistance in Mycobacterium tuberculosis Egypt J Chest Dis Tuberc. 2017; 66, 425-427.

[16] Liu, Z., Zhang, M., Wang, J., Chen, S., Wu, B., Zhou, L., Pan, A., Wang, W., \& Wang, X. Longitudinal

Analysis of Prevalence and Risk Factors of Rifampicin-Resistant Tuberculosis in Zhejiang, China. BioMed research international. 2020; 3159482-8.

[17] Tadesse M, Aragaw D, Dimah B, Efa F, Abdella K, Kebede W, Abdissa K, Abebe G. Drug resistanceconferring mutations in Mycobacterium tuberculosis from pulmonary tuberculosis patients in Southwest Ethiopia. Int J Mycobacteriol. 2016 Jun;5(2):185-91.

[18 Ochang EA, Udoh UA, Emanghe UE, Tiku GO, Offor JB, Odo M. Evaluation of rifampicin resistance and 81-bp rifampicin-resistant determinant region of $r p o B$ gene mutations of Mycobacterium tuberculosis detected with Xpert MTB/RIF in Cross River state, Nigeria. Int J Mycobacteriology. 2016; 5:145-6.

[19] Mboowa G, Namaganda C, Sengooba W. Rifampicin resistance mutations in the 81 bp RRDR of $r p o B$ gene in Mycobacterium tuberculosis clinical isolates using Xpert® MTB/RIF in Kampala, Uganda: a retrospective study. BMC Infect Dis. 2014;14:481.

[20] Rahman A, Sahrin M, Afrin S, Earley K, Ahmed S, Rahman SM, Banu S. Comparison of Xpert MTB/RIF Assay and GenoType MTBDRplus DNA Probes for Detection of Mutations Associated with Rifampicin Resistance in Mycobacterium tuberculosis. PLoS One. 2016 Apr 7;11(4):e0152694.

[21] Chikaonda T, Ketseoglou I, Nguluwe N, Krysiak R, Thengolose I, Nyakwawa F, Rosenberg NE, Stanley C, Mpunga J, Hoffman IF, Papathanasopoulos MA, Hosseinipour M, Scott L, Stevens W. 
Molecular characterisation of rifampicin-resistant Mycobacterium tuberculosis strains from Malawi. Afr J Lab Med. 2017;6(2):463.

[22] Metcalfe JZ, Makumbirofa S, Makamure B, Sandy C, Bara W, Mason P, Hopewell PC. Xpert(®) MTB/RIF detection of rifampin resistance and time to treatment initiation in Harare, Zimbabwe. Int J Tuberc Lung Dis. 2016;20(7):882-9. 